\title{
TRANSFORMATION OF SHUTTLE RADAR TOPOGRAPHY MISSION (SRTM) DIGITAL ELEVATION DATA TO NIGERIAN HEIGHT SYSTEM
}

\author{
Nwilo P.C, Olayinka D. N., Okolie C. J. and Adzandeh E. A. \\ Department of Surveying and Geoinformatics, University of Lagos, Lagos- Nigeria.
}

\begin{abstract}
Determination of height information using the classical field surveying and geodetic methods is rather expensive, rigorous and time consuming. It is also limited in the capacity of the earth surface data gathered. These conventional topographic mapping technologies have produced maps with a variety of scales and of uneven quality - some with astounding accuracy, some far less adequate. A good alternative is the Shuttle Radar Topography Mission (SRTM) derived Digital Elevation Model (DEM) which provides an excellent base data for extracting heights for topographic mapping. This will ameliorate the present situation. The SRTM space mission produced the most complete, highest resolution digital elevation model of the Earth. This study is aimed at developing a model for the transformation of the SRTM heights from WGS84 datum to the Nigerian height system (Minna datum) using SRTM derived DEM, topographic map and Global Positioning System (GPS) data of some parts of Lagos state, Nigeria. The chosen site corresponds to the area covered by one map sheet at the scale of 1:25,000 $(13.8 \mathrm{~km} \times 13.8 \mathrm{~km})$ which is 190.44sq.km. Software such as Globalmapper, Surfer 8.0 and ArcGIS 9.3 were used for specialized data processing and analysis. However, the datasets obtained were first projected to a common system and subsequently harmonized. This was carried out with an overlay of GPS points on the grid based SRTM and topographic DEM surfaces of the environment. Results showed deviation in heights with coinciding planimetry data. The average absolute error of the SRTM DEM for our test site was gotten as $+1-0.22087 \mathrm{~m}$. Finally, by modelling this vertical shift, a transformation model that is accurate with a standard error of $0.238 m$ was developed.
\end{abstract}

Key Words: Digital Elevation Model, SRTM, Topographic Data, WGS 84, Minna Datum,

\section{Introduction}

An accurate description of the surface elevation of the earth is of fundamental importance to many branches of Earth Science. At the foundation of modern geosciences, quite literally, is knowledge of the shape of the earth's surface. From hydrologic models of flooding and runoff, to atmospheric boundary layer friction theories, the earth's topography is an essential constraint and boundary condition (Farr et al., 2000). Topography is basic to many earth surface processes. It is used in analyses in ecology, hydrology, agriculture, climatology, geology, pedology, geomorphology, and many others, as a means both of explaining processes and of predicting them through modelling. Our capacity to understand and model these processes depends on the quality of the topographic data that are available (Jarvis et al., 2004). There is an obvious practical importance to a high-quality global digital elevation model (DEM) as well. DEMs can be generated using remote sensing techniques, field surveys and/or digitizing of topographic maps.

Conventional topographic mapping technologies have produced maps of different quality - some with astounding accuracy, some far less adequate. Most industrial countries have created and maintained national cartographic databases. The map products derived from these databases have demonstrated the idiosyncrasies of these conventional topographic data. The maps are at a variety of scales and resolutions, often referenced to country-specific datums and thus inconsistent across national boundaries 
(Farr et al., 2000). Furthermore, the global coverage has been uneven. In many parts of the world, particularly cloudy parts of South America and Africa, very little high quality topographic data exist.

It has proven exceedingly difficult and expensive to produce a global map set or digital elevation model of consistent scale and resolution by conventional means. The cost of deploying aircraft globally is prohibitive, and many areas are inaccessible politically. Optical stereo mapping systems suffer from poor control and matching difficulties in areas of low contrast, and from persistent cloud cover in many important areas of the world.

The only practical way to produce a globally consistent topographic data set is by employing a globally consistent mapping technique (Farr et al., 2000). The emergence, in the 1990s, of synthetic aperture radar (SAR) interferometry (Zebker et al., 1986; Massonnet, 1997; Madsen et al., 1998; Rosen et al., 2000) placed the possibility of efficiently and affordably creating a global digital elevation model within the grasp of space-faring nations. The Shuttle Radar Topography Mission (SRTM) demonstrated the power of the new technique.

\section{The Shuttle Radar Topography Mission}

The Shuttle Radar Topography Mission was an 11-day mission flown on Space Shuttle Endeavour (STS-99) in February 2000. The project was a joint endeavour of the National Aeronautics and Space Administration (NASA), the National GeospatialIntelligence Agency, NGA (formerly National Imagery and Mapping Agency, NIMA) of the US. Department of Defense (DoD), the German Aerospace Centre (DLR) and the Italian Space Agency (ASI). The Jet Propulsion Laboratory (JPL), California Institute of Technology, manages the Shuttle Radar Topography Mission for NIMA and NASA as part of its Earth Science programme. This programme uses data from satellites, aircraft, and ground research to help scientists better understand Earth's systems of land, water, air, and life, how they interact, and are changing. SRTM used dual radar antennas to acquire interferometric radar data (InSAR), processed to digital topographic data.

The data currently being distributed by NASA/USGS (finished product) contains "no-data" holes where water or heavy shadow prevented the quantification of elevation. These are generally small holes, which nevertheless render the data less useful, especially in fields of hydrological modelling. This original SRTM data has been subjected to a number of processing steps by the Consultative Group for International Agricultural Research Consortium for Spatial information (CGIAR-CSI) to provide seamless and complete elevation surfaces for the globe. For the CGIAR-CSI SRTM data product, a hole-filling algorithm was applied to provide continuous elevation surfaces. The final seamless dataset with voids filled in is available at the website of the Consultative Group for International Agricultural Research Consortium for Spatial information (CGIAR-CSI) via http://srtm.csi.cgiar.org.

The dataset compiled by CGIAR-CSI has advantages of being seamless; preprocessed for immediate use; available in GeoTiff format which is supported by most GIS applications; easy to download specific DEMS of interest as the interface is very user-friendly and the CGIAR website provides extensive documentation on the voidfilling process for the SRTM. These advantages make CGIAR-CSI SRTM data product a valuable resource, especially for cases when analysis of terrain had to be done promptly, for example, during Asian Tsunami of 2004 (Blumberg et al., 2005). 


\section{Statement of Problem and Justification for the Study}

Determination of height information using the classical field surveying and geodetic methods is rather expensive and time consuming. It is also limited in the capacity of the earth surface data gathered in the process. Control extension using aero-triangulation is less expensive but might not be cost-effective for small departmental mapping projects with tight budgeting constraints. A good alternative is to adopt free spatial data sources such as the Shuttle Radar Topography Mission (SRTM) DEM which provides an excellent base data for extracting heights for topographic mapping. This will drastically reduce the cost of mapping at small and medium scales. Partial accuracy assessments of this product have been done by several researchers including the Centro Internacional de Agricultura Tropical (CIAT) in South America to verify the performance of the developed SRTM DEM, but the global user community would gain more benefits from other regional assessments.

The SRTM DEM, if transformed to the Nigerian height system will serve as a less costly and rapidly deployable source of elevation data for topographic mapping of extensive areas.

It is on this basis that we seek to embark on this research in order to come up with a model that will conveniently transform the SRTM height data to their equivalent Nigerian height system.

\section{Aim and objectives of the study}

The aim of this study is to develop a model for the transformation of the Shuttle Radar topography heights from WGS84 datum to the Nigerian height system (Minna datum).

The objectives of the study are:

- To compare absolute and relative differences between the $1 / 25,000$ cartographically generated DEM and the SRTM DEM using the field-based GPS surveys as a baseline;

- To comparatively analyse the cartographic quality of the topographic map and SRTM derived DEMS.

- To test the accuracy of the derived model

\section{Study Area}

The site chosen for this study lies between Latitudes $6^{\circ} 30^{\prime} 00^{\prime \prime} \mathrm{N}$ and $6^{\circ} 37^{\prime} 30^{\prime \prime} \mathrm{N}$ and Longitudes $3^{\circ} 15^{\prime} 00^{\prime \prime} \mathrm{E}$ and $3^{\circ} 22^{\prime} 30^{\prime \prime} \mathrm{E}$ within Lagos state, Nigeria. The chosen site corresponds to the area covered by one map sheet at the scale of $1 / 25,000(13.8 \mathrm{~km} x$ $13.8 \mathrm{~km}$ ). which is approximately $190.44 \mathrm{sq} . \mathrm{km}$. The study area is at the central part of Metropolitan Lagos. 


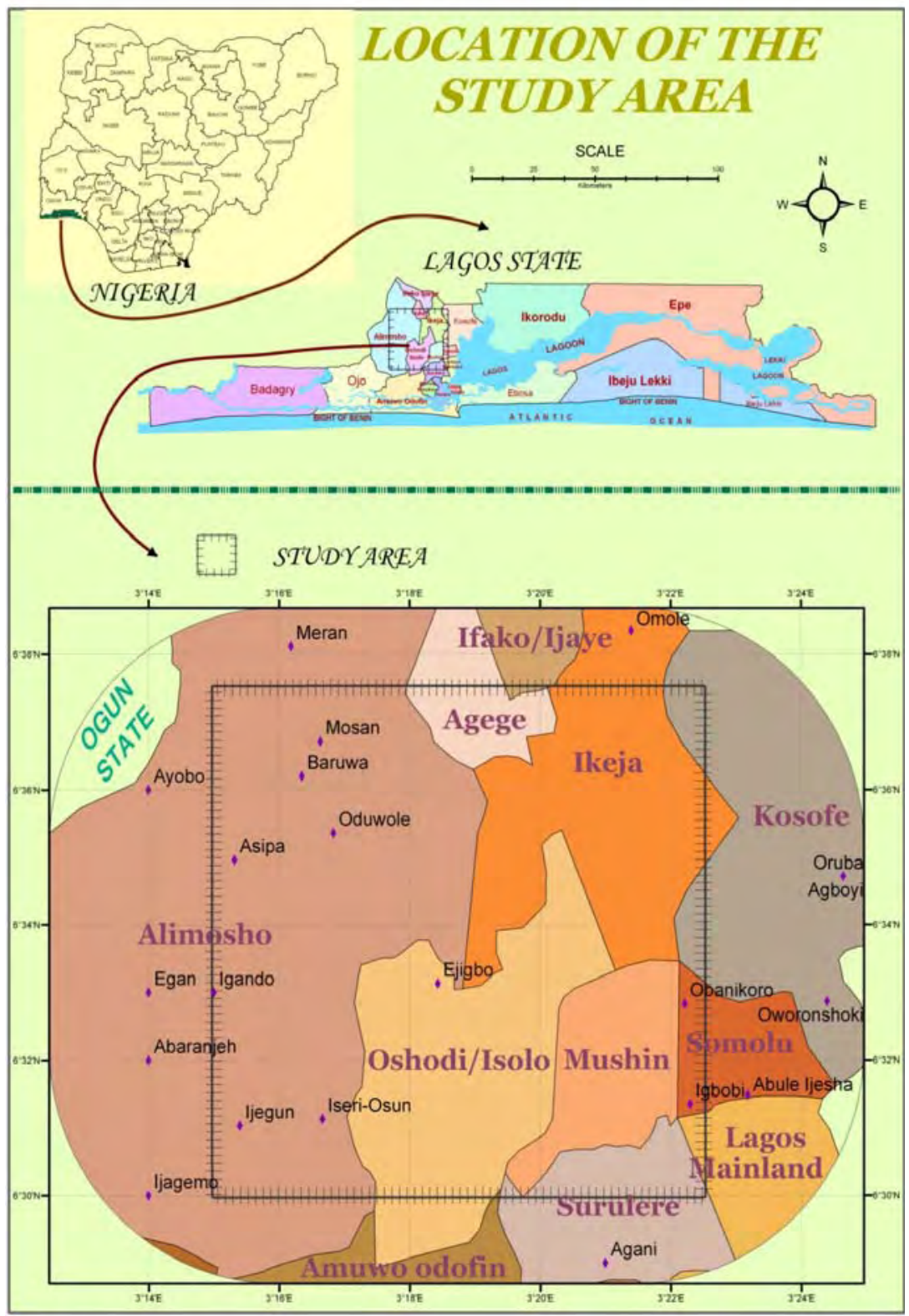

Figure 1: The study area

The study area cuts across ten different Local Government Areas (LGAs). These areAlimosho, Oshodi- Isolo, Ikeja, Mushin, Surulere, Agege, Somolu, Lagos Mainland, Kosofe and Ifako ljaiye. Some important towns in this area are Ejigbo, Igando, Ijegun and Iseri-osun. The site covers low-level altitude terrain with elevations ranging from $2 \mathrm{~m}$ to $45 \mathrm{~m}$ above mean sea level.

\section{Methodology}

The methodology employed for this study includes analytical techniques inherent in a Geographic Information System (GIS) and also incorporates several statistical relations used for accuracy assessments.

\section{Data Acquisition}

Three major datasets used for the study were 3 arc second (90m resolution) CGIARCSI SRTM digital elevation data, 1/25,000 topographic map of the study area and 
randomly distributed GPS point data covering the study area. The data were acquired from different sources. Table 1 presents the data-sets and their sources.

Table 1: Datasets used and sources

\begin{tabular}{|l|l|l|l|}
\hline Data set & Source & $\begin{array}{l}\text { Scale/ } \\
\text { Resolution/Order }\end{array}$ & Format \\
\hline $\begin{array}{l}\text { SRTM DEM } \\
\text { (version 4.1) }\end{array}$ & $\begin{array}{l}\text { Consultative Group for International } \\
\text { Agricultural Research - Consortium for } \\
\text { Spatial Information (CGIAR-CSI) }\end{array}$ & $\begin{array}{l}90 \mathrm{~m} \\
\text { resolution }\end{array}$ & GeoTIFF \\
\hline $\begin{array}{l}\text { Topographic map } \\
\text { (Sheet 279 SE 3) }\end{array}$ & Federal Surveys, Lagos State & $1 / 25,000$ & JPEG \\
\hline $\begin{array}{l}\text { GPS point data } \\
\text { (Differential GPS) }\end{array}$ & Interspatial Technologies Ltd & $1 \mathrm{st} / 2^{\text {nd }}$ order & Hardcopy \\
\hline
\end{tabular}

The SRTM data is provided in a geographic coordinate system (latitude and longitude) and as $5^{\circ} \times 5^{\circ}$ tiles in computer compatible raster formats (GeoTiff and ARCINFO ASCII Grid). The data was downloaded in GeoTiff format.

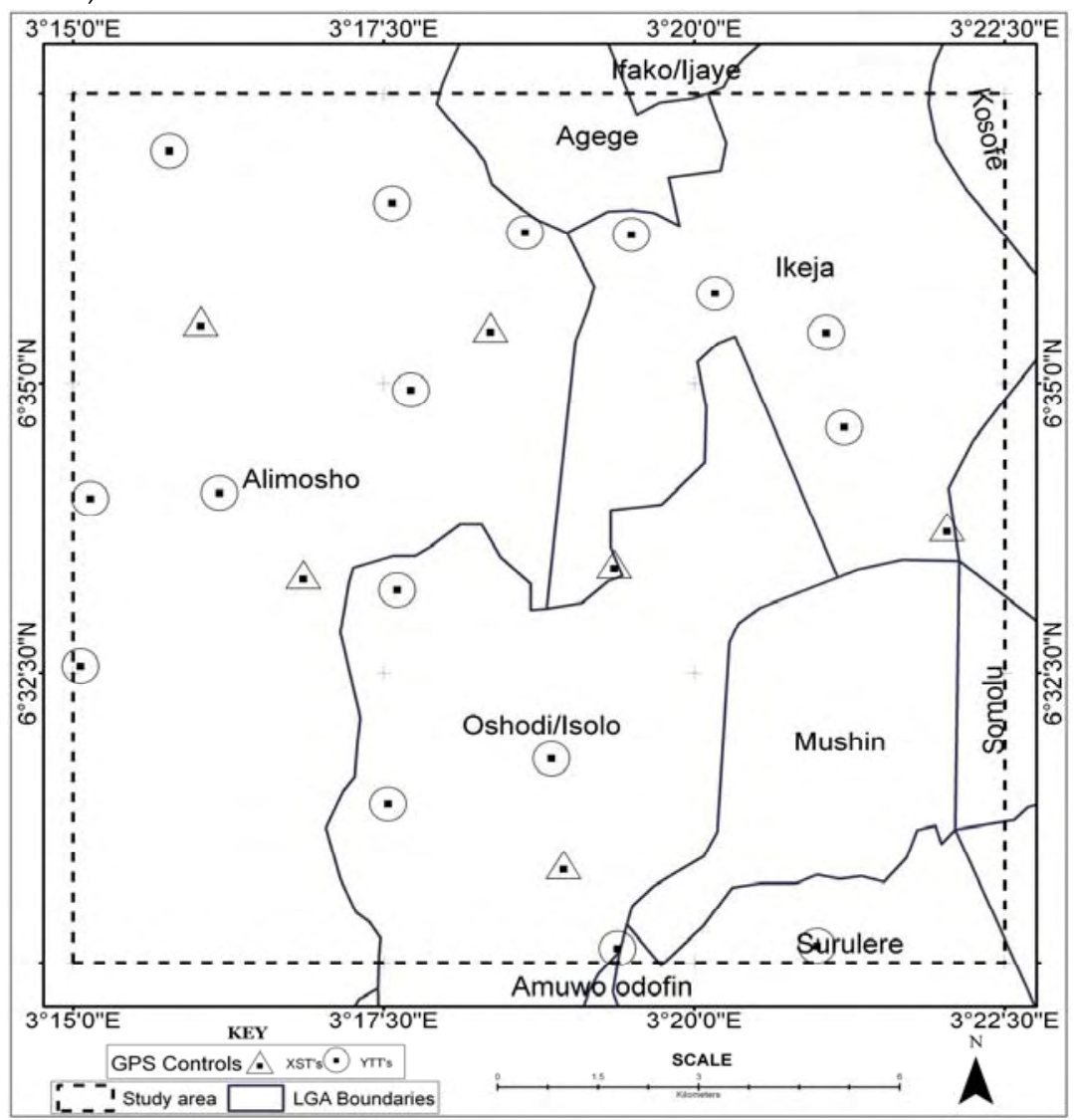

Figure 2: Spatial distribution of the GPS points within the study area

The topographic map sheet at a scale of 1/25,000 covering the chosen study area was selected for use due to its abundance of hypsometry layers (contours and spot heights). The DGPS control points are important due to their high positional (horizontal and vertical) accuracy ( $1^{\text {st }}$ and $2^{\text {nd }}$ order). The DGPS was used as a baseline for assessing the accuracies of both the SRTM and topographic map DEMS. 


\section{Hardware and Software used}

The hardware includes all the devices used to acquire, store, process data and display the information obtained in the course of the study. These include:

- The data acquisition hardware, handheld GPS receiver.

- A computer laptop for the storage and manipulation of data

- The output hardware (such as graphic display unit of the laptop, printers and plotters)

The following software were employed for the numerous manipulation and analytical tasks carried out on the raw datasets in this study:

- $\quad$ AutoDesk Raster Design 2006

- $\quad$ ArcGIS 9.3

- Global Mapper 11.0

\section{Coordinate System and Data Integration}

The SRTM data is provided in a geographic coordinate system (lat/long) referenced to WGS84 datum and is referenced to mean sea level realized by the EGM 96 geoid model (Lemoine et al., 1998). Hence, the DEM is provided in terms of orthometric heights. The topographic map is on a Universal Traverse Mercator grid (UTM Zone $31 \mathrm{~N}$ ) referenced to Minna datum and based on the Clarke 1880 ellipsoid. Its heights are orthometric and it has a contour interval of 5 metres. There are several spot heights on the map. For ease of overlay with the SRTM DEM, the geographic coordinates on the topographic map were used in georeferencing. The DGPS controls gotten from Interspatial Technologies were supplied with both their ellipsoidal and corresponding orthometric heights. Thus orthometric heights are available for the three (3) datasets. Coordinate system and the datum information for the data used are as shown in Table 2.

Table 2: Coordinate system and Datum information for the datasets

\begin{tabular}{|l|l|l|l|}
\hline Data set & Coordinate system & Datum & Height system \\
\hline SRTM DEM & Geodetic $(\phi, \lambda, H)$ & WGS84 & Orthometric \\
\hline $\begin{array}{l}\text { Topographic map (Sheet } \\
\text { 279 SE 3) }\end{array}$ & Geodetic $(\phi, \lambda, H)$ & Minna & Orthometric \\
\hline DGPS elevations & Geodetic $(\phi, \lambda, H)$ & Minna & Ellipsoidal/orthometric \\
\hline
\end{tabular}


Table 3: Parameters of Station Coordinates

Coordinates of the GPS Controls used for the study

\begin{tabular}{|c|c|c|c|c|c|c|c|c|}
\hline \multirow[b]{2}{*}{$\mathbf{S} / \mathbf{N}$} & \multirow[b]{2}{*}{ STATION } & \multicolumn{2}{|c|}{ MINNA DATUM } & \multicolumn{2}{|c|}{ WGS84 DATUM } & \multirow[b]{2}{*}{$\mathrm{H}_{\mathrm{GPS}}(\mathrm{m})$} & \multirow[b]{2}{*}{ Нторо (m) } & \multirow[b]{2}{*}{$\mathrm{H}_{\text {SRTM }}(\mathrm{m})$} \\
\hline & & $\varphi^{\circ}$ & $\lambda^{0}$ & $\varphi^{\circ}$ & $\lambda^{0}$ & & & \\
\hline 1 & XST 103 & 6.55583 & 3.28092 & 6.55626 & 3.28015 & 18.75322 & 16.62900 & 19.92300 \\
\hline 2 & XST 104 & 6.5923 & 3.26715 & 6.59272 & 3.26639 & 32.17603 & 35.13700 & 33.42200 \\
\hline 3 & XST 106 & 6.51402 & 3.31586 & 6.51445 & 3.31509 & 4.51724 & 4.74000 & 6.44000 \\
\hline 4 & XST 111 & 6.55731 & 3.32265 & 6.55773 & 3.32188 & 14.87614 & 15.21200 & 15.89500 \\
\hline 5 & XST 112 & 6.5914 & 3.30602 & 6.59182 & 3.30525 & 34.26501 & 35.00000 & 35.75100 \\
\hline 6 & XST 117 & 6.56263 & 3.36728 & 6.56305 & 3.36651 & 29.07893 & 28.04200 & 28.52600 \\
\hline 7 & YTT 2843 & 6.55363 & 3.29352 & 6.55405 & 3.29276 & 26.47900 & 26.22300 & 27.69500 \\
\hline 8 & YTT 2871 & 6.54264 & 3.25101 & 6.54306 & 3.25024 & 12.38260 & 12.23900 & 14.28600 \\
\hline 9 & YTT 2878 & 6.52282 & 3.29231 & 6.52324 & 3.29154 & 13.75380 & 16.78100 & 12.90900 \\
\hline 10 & YTT 2881 & 6.56677 & 3.25235 & 6.56719 & 3.25158 & 22.57890 & 27.82400 & 23.47300 \\
\hline 11 & YTT 2898 & 6.61675 & 3.26295 & 6.61716 & 3.26219 & 10.62630 & 11.96700 & 12.20800 \\
\hline 12 & YTT 28102 & 6.60927 & 3.29283 & 6.60968 & 3.29206 & 35.93020 & 34.29000 & 37.08000 \\
\hline 13 & YTT 28104 & 6.56759 & 3.26966 & 6.56801 & 3.2689 & 32.05270 & 30.00000 & 33.11700 \\
\hline 14 & YTT 28125 & 6.60505 & 3.31069 & 6.60547 & 3.30993 & 42.00450 & 38.11000 & 42.71700 \\
\hline 15 & YTT 28127 & 6.60476 & 3.32494 & 6.60518 & 3.32417 & 23.12370 & 23.08000 & 23.24300 \\
\hline 16 & YTT 28129 & 6.58238 & 3.29535 & 6.58279 & 3.29459 & 32.58320 & 34.43000 & 34.52900 \\
\hline 17 & YTT 28134 & 6.52932 & 3.31422 & 6.52974 & 3.31346 & 4.17030 & 5.00000 & 4.26400 \\
\hline 18 & YTT 28136 & 6.59625 & 3.33615 & 6.59666 & 3.33538 & 38.65140 & 37.94200 & 38.91400 \\
\hline 19 & YTT 28138 & 6.59065 & 3.35106 & 6.59106 & 3.3503 & 33.53020 & 34.91000 & 34.76900 \\
\hline 20 & YTT 28139 & 6.57694 & 3.3535 & 6.57736 & 3.35274 & 31.77020 & 32.51200 & 32.92800 \\
\hline 21 & YTT 28148 & 6.50202 & 3.32307 & 6.50245 & 3.3223 & 4.70330 & 4.89500 & 3.88400 \\
\hline 22 & YTT 28179 & 6.5024 & 3.34986 & 6.50282 & 3.3491 & 5.65030 & 4.38000 & 7.21800 \\
\hline
\end{tabular}

\section{Data Manipulation and Analysis}

The topographic map acquired was georeferenced using the geographic coordinates $(\phi, \lambda)$ of its border points in ArcGIS 9.3. After rubbersheeting the map, an "adjust" transformation was used to minimize the total RMS error. The adjust transformation optimizes for both global least squares fitting (LSF) and local accuracy. It is built on an algorithm that combines a polynomial transformation and triangulated irregular network (TIN) interpolation techniques. The adjust transformation performs a polynomial transformation using two sets of control points and adjusts the control points locally to better match the target control points using a TIN interpolation technique. To use 'Adjust', a minimum of three control points was required. After georeferencing, the map was referenced to Minna datum on ArcCatalog.

The hypsometry layers (contours and spot heights) were digitized using AutoDesk RasterDesign while attributes were inputted in Arcmap. The elevations of all contours and spot heights were used in creating a DEM. Using the hypsometry layers, a 
triangulated irregular network was created. Then it was reclassed into a raster and assigned the same spatial resolution $(90 \mathrm{~m})$ as the SRTM DEM.

It was necessary to extract 2 sets of points both from the SRTM and topographic map which are coincident with the GPS points. On the topographic map, this was done by:

- Creating a triangulated irregular network (TIN) using the height values of the contours and spot heights

- Converting the TIN to a raster by using 'tin to raster' tool in ArcGIS 3D Analyst. The 'tin to raster' tool converts a TIN to a raster through interpolation. Every cell in the output is assigned a height or a NoData value depending on whether or not the cell center falls within the TIN's interpolation zone. The pixel resolution was set to $90 \mathrm{~m}$ to conform with that of the SRTM.

- The resultant raster (tinraster) was inputted on Globalmapper from where the heights were extracted one at a time. To do this, the control points were overlaid on the tinraster surface. Then by zooming in as much as possible into the tinraster until the minimum spatial resolution obtainable was met, the heights of such points were recorded.

The TIN is presented as a graduated colour map with z-values spread across ten (10) classes ranging from $2-47$ metres. It was necessary to create the TIN so as to have a continuous field of elevation values that vary over an infinite number of points. Because the TIN contains an infinite number of points, it is impossible to measure and record the z-value at every point. The TIN approximates the surface by taking a sample of the zvalues at different points on the surface and interpolating the values between these points. It can be seen clearly in Figure 5 that the created TIN is in the form of a hard and soft edge breaklines structure. It has to be converted to a cell structure so that it can be assigned the same 90m spatial resolution as the SRTM DEM. To achieve this, the 'tin to raster' tool in ArcGIS 3D Analyst was used to convert it to a raster surface (Figure 6).

For the SRTM DEM, a different procedure was adopted. The SRTM DEM is referenced to WGS84. The differences between GPS coordinates in Minna and WGS84 datum were averaged. The average of the differences (i.e., $\Delta \phi_{\text {MINNA-WGS84 }}$ and $\Delta \lambda_{\text {MINNA- }}$ wGS84) were then added to all the GPS Minna coordinates in order to get their WGS84 equivalents. The WGS84 equivalents were then overlaid on the SRTM DEM for height

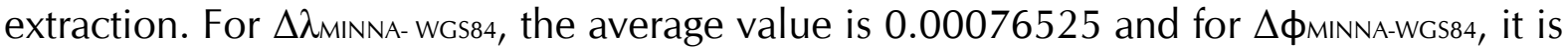
-0.00024286 .

\section{Accuracy Assessments}

"Errors" are operationally defined as discrepancies between elevation from the SRTM data and corresponding GPS measurements which are assumed to be accurate and, thus, are used as reference values (Gorokhovich et al, 2006). Determining the average absolute error of SRTM data basically involves computing the standard error statistic of the vertical errors between the SRTM data and the reference data set (GPS points). This same procedure applies to the topographic DEM data. 


\section{Results and Discussion}

\section{Results}

The surface heights gotten independently from SRTM and the topographic map were cross-validated. Twenty-two (22) GPS controls were used as control data for assessing the accuracy of the SRTM and topographic map DEMs. The ellipsoidal and orthometric heights of the GPS controls were provided.

\section{Comparison with GPS determined heights}

A simple regression plot of the coordinates in both datum yielded the following corrective equations ( 1 and 2 ):
$\lambda_{W}=\lambda_{M}+0.0008$
$\phi w=1.0001 \phi_{M}-0.0012$
where,
$\lambda w=$ longitude (WGS84 datum)
$\phi w=$ latitude (WGS84 datum)
$\lambda_{M}=$ longitude (Minna datum)
$\phi_{M}=$ latitude (WGS84 datum)

The regression plots are as shown in Figures 3 and 4 .

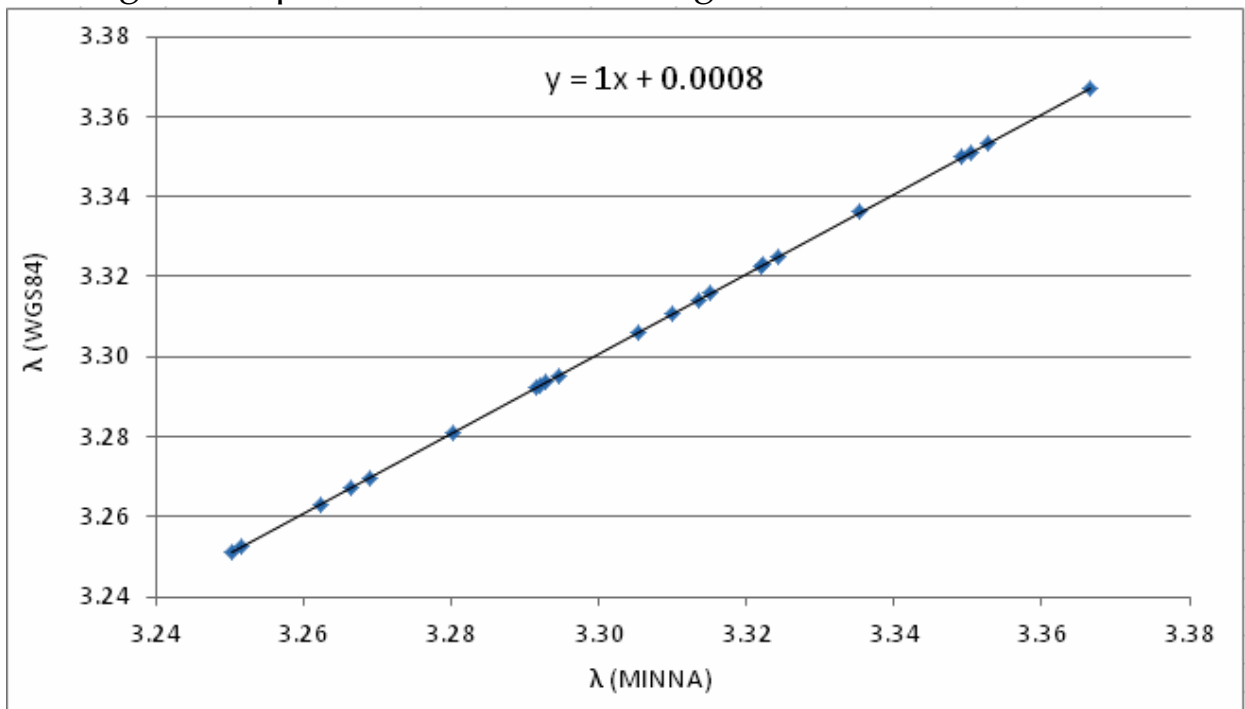

Figure 3: Regression plot of $\lambda_{w}$ against $\lambda_{M}$

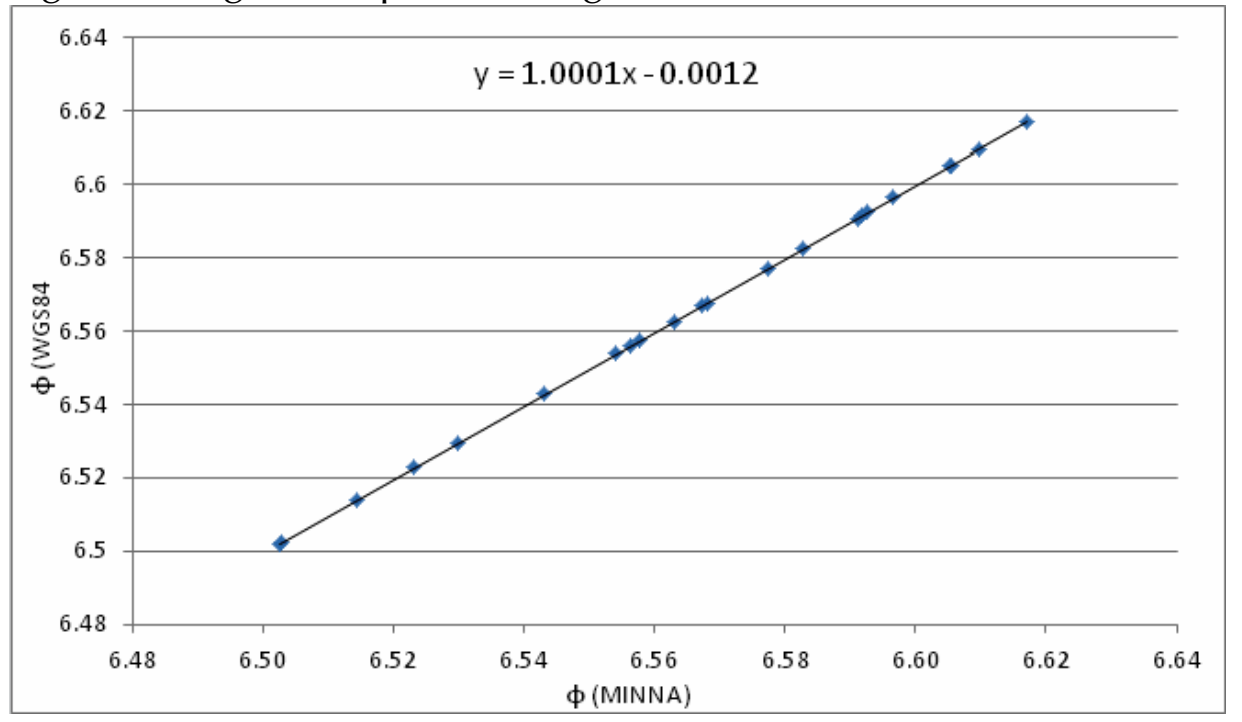


Figure 4: Regression plot of $\phi_{\mathrm{w}}$ against $\phi_{\mathrm{M}}$

\section{Extraction of heights from the topographic map and SRTM}

Figure 5 shows an overlay of the hypsometry layers (contours and spot heights) on the TIN. Analysis of Figure 5 shows that the area is relatively flat with gentle slopes. Elevation ranges from as low as 2 metres in the south to as high as 47 metres in the far north. The mean spot height elevation is 22.4 metres while the contours have a mean elevation of 21.8 metres.

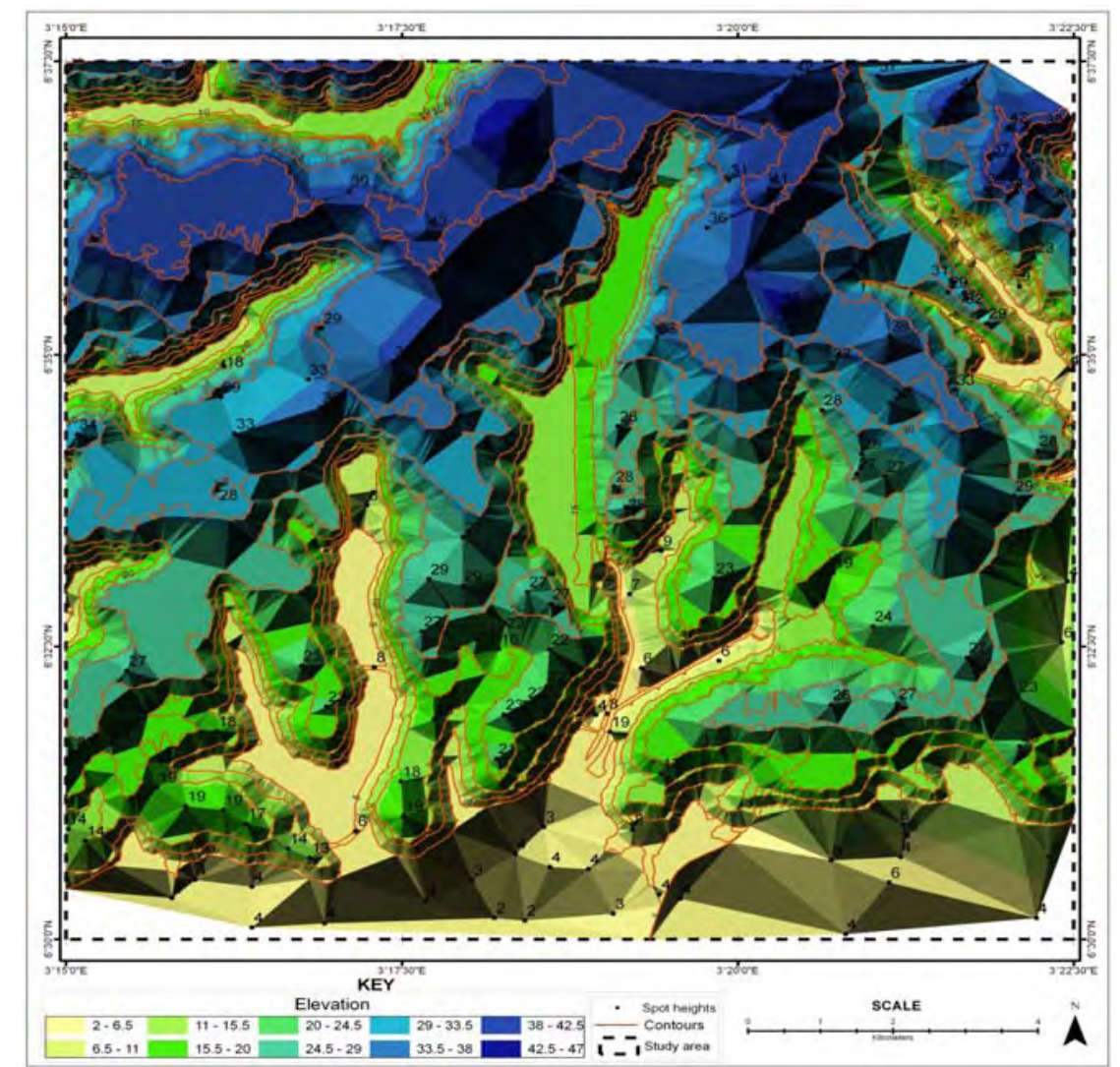

Figure 5: Overlay of the hypsometry layers on the TIN

Because interpolation of the input TIN surface occurs at regular intervals when using 'tin to raster', there was some loss of information in the output raster. How well the raster represents the TIN is dependent on the resolution of the raster and the degree and interval of TIN surface variation. Generally, as the resolution is increased, the output raster more closely represents the TIN surface. As with the original TIN, the rasterised TIN is classed into ten regions ranging from about $2-47$ metres. Analysis of Figure 6 shows that the class boundaries closely follow the contour outlines.

The lowest areas ( $2-17$ metres) are found mostly in the southern portion of the map. The GPS points were overlaid on this rasterised TIN on Global Mapper package for

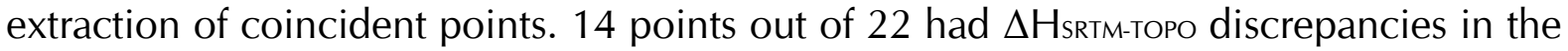
range of $+/-2 \mathrm{~m}$. All points with discrepancies falling outside this range were eliminated before the corrective equation for the SRTM-Topo transformation was derived. 


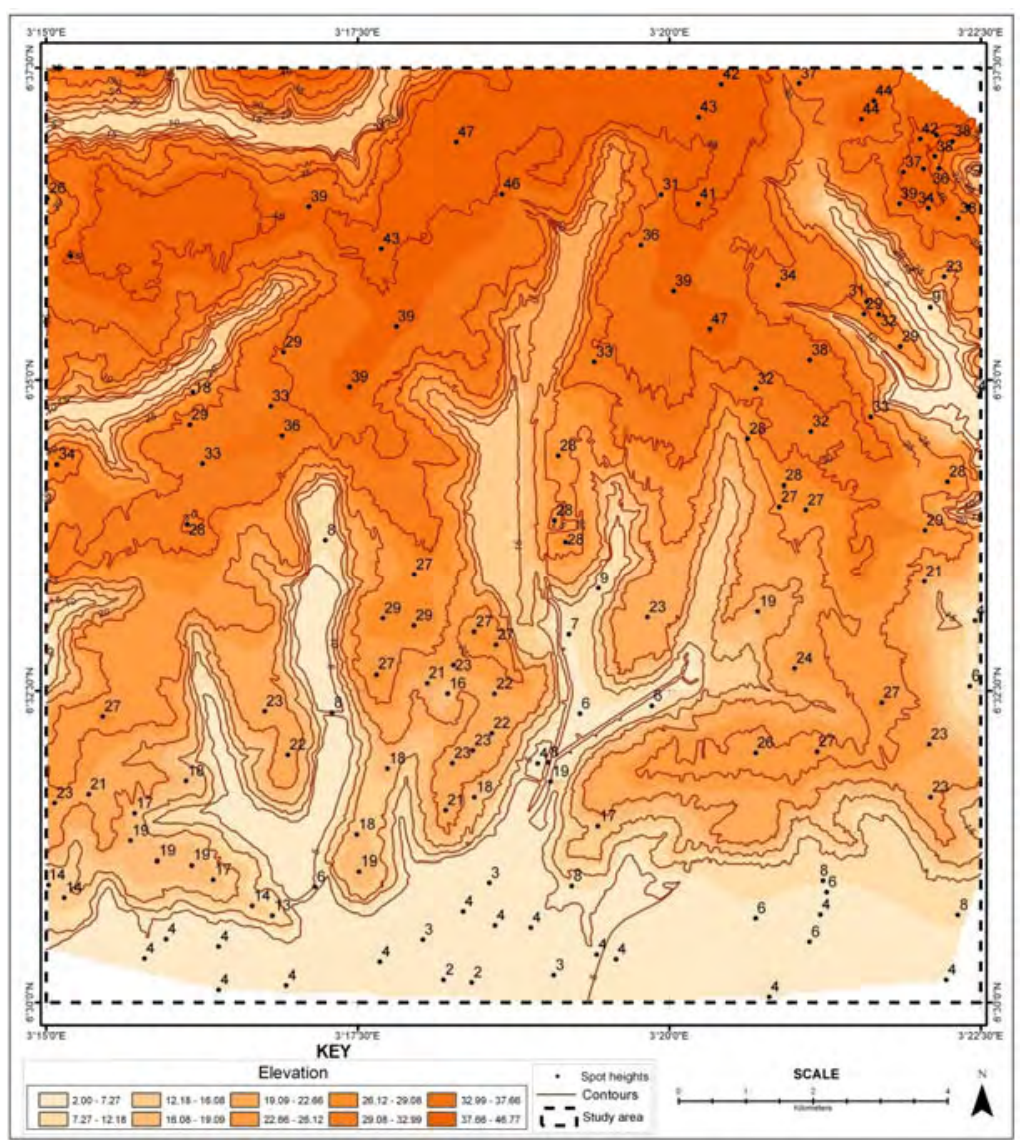

Figure 6: Overlay of the hypsometry layers on the rasterised TIN

\section{Assessment of Accuracy}

One of the most accurate measures of the height performance of SRTM over typical land surfaces is by comparing it with differential GPS controls. Assessment of the accuracy of SRTM model and topographic map DEM was presented by computation of standard error of the mean (or standard error), standard deviation and absolute difference between the height values ( $\mathrm{H}_{\text {sRTM }}$ and $\mathrm{H}_{\text {TOPO}}$ ) and the GPS check point values (HGPs). The results are presented in Table 3 
Table 3: Descriptive statistics of the difference in distance between limits.

\begin{tabular}{|l|l|l|l|}
\hline Parameter & $\mathbf{\Delta} \mathbf{H}_{\text {GPS-TOPO }}(\mathbf{m})$ & $\mathbf{\Delta} \mathbf{H}_{\text {GPS-SRTM }}(\mathbf{m})$ & $\mathbf{\Delta} \mathbf{H}_{\text {SRTM-TOPO }}(\mathbf{m})$ \\
\hline Standard deviation & 1.0486 & 0.8798 & 0.9300 \\
\hline Variance & 1.0996 & 0.7740 & 0.8649 \\
\hline Range & 3.9979 & 2.7651 & 3.4150 \\
\hline Minimum & -2.9610 & -1.9458 & -1.7150 \\
\hline Maximum & 1.0369 & 0.8193 & 1.7000 \\
\hline Standard Error & 0.2803 & 0.2351 & 0.2486 \\
\hline
\end{tabular}

For $\Delta \mathrm{H}_{\mathrm{GPS} \text {-TOPO, }}$ the standard error is $0.2803 \mathrm{~m}$. For $\Delta \mathrm{H}_{\mathrm{GPS}-\mathrm{SRTM}}$, the standard error is $0.2351 \mathrm{~m}$ while $\Delta \mathrm{H}_{\text {SRTM-TOPO }}$ has a standard error of $0.2486 \mathrm{~m}$. The results show that the average absolute error of the SRTM DEM for our test site is $+/-0.2351 \mathrm{~m}$ and the average absolute error of the topographic DEM for our test site is $+/-0.2803 \mathrm{~m}$. The terrain heights statistics from the topographic map based model revealed that the minimum elevation was $4.74 \mathrm{~m}$ while the maximum was $37.942 \mathrm{~m}$. From the SRTM based model, the minimum was $3.884 \mathrm{~m}$ while the maximum height was $38.914 \mathrm{~m}$.

Visualization of vertical errors revealed lack of uniform distribution of the errors across terrain. Figure 7 shows a superimposition of the GPS, SRTM and topographic map heights. Greater error values were associated with rugged terrain, while smaller error values were associated with flat areas, suggesting that such terrain characteristics as slope and aspect can influence CGIAR CSI SRTM accuracy. It is clear that the planimetric coordinates $(x, y)$ of the SRTM DEM and the topographic map coincide, but elevation has deviations. It is obvious also that majority of all the height differences are within $\mathrm{a}+/-5 \mathrm{~m}$ band. For $\Delta \mathrm{H}_{\mathrm{GPS}-\mathrm{TOPO}}$ and $\Delta \mathrm{H}_{\mathrm{GPS}-S \mathrm{RTM}}$, the large positive differences indicate areas where the published height of the GPS points is above the height of the SRTM/topographic map.

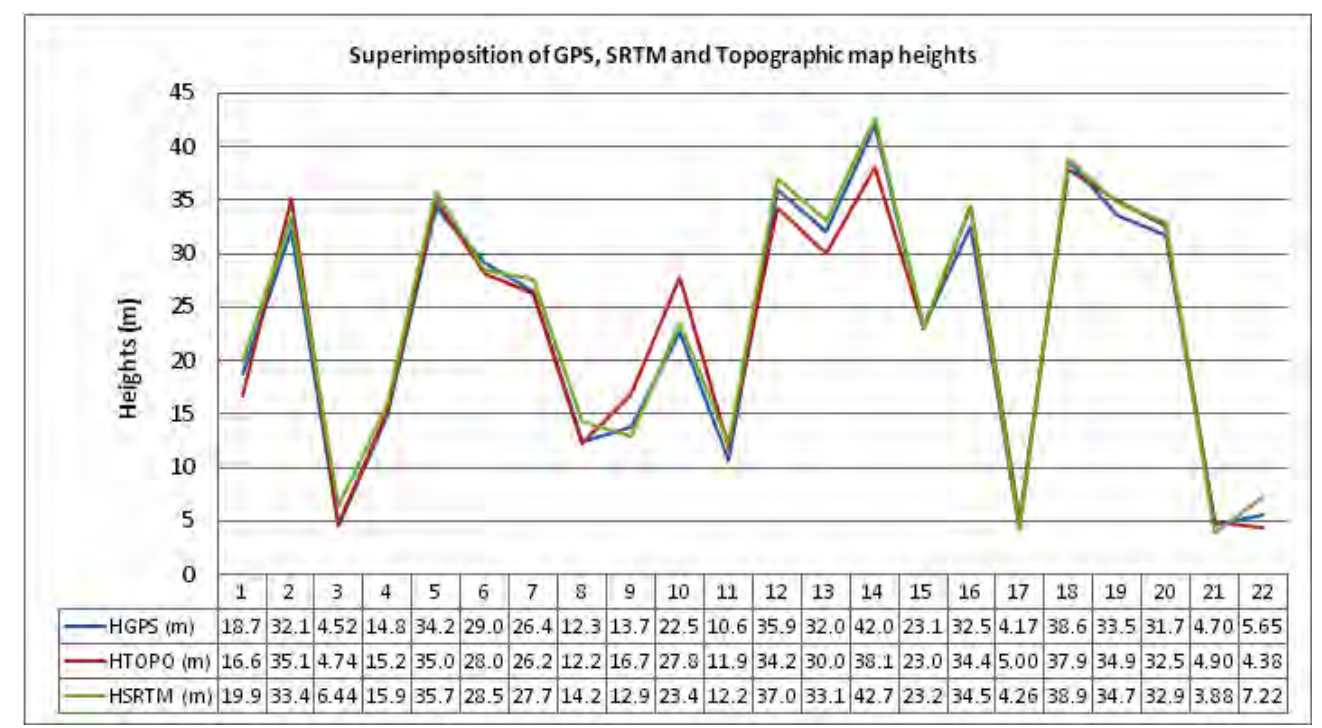

Figure 7: Superimposition of GPS, SRTM and Topographic map heights

Also, the SRTM elevation data represent a digital surface model, whereas the reference GPS data and topographic map data describe the terrain. These considerations lead to the problem of comparing two data sets with different elevation definitions. Since the GPS data is limited to roads and open spaces, it will selectively avoid areas of 
radar shadow (terrain noise). Thus, the estimates presented in Table 3 may be optimistic for this region.

Analysis of Figure 7 shows a high positive correlation between the heights of the three datasets in most areas. It can be seen that the SRTM values show a higher level of agreement than the topographic map heights. Examination of these results shows some consistencies in behaviour for the standard deviations and absolute errors. It can be further inferred from the standard deviation of the height differences that the absolute accuracy of SRTM height is better than the SRTM mission specifications $(16 \mathrm{~m})$. The SRTM height bias caused by buildings and forest cover needs to be further examined using future Spaceborne LIDAR.

Of the 22 GPS points, the SRTM elevation values were closer to the GPS elevation values on 12 occasions (54.54\%). The average difference between SRTM and GPS elevations was $0.888 \mathrm{~m}$, whereas the difference between TOPO and GPS elevations was $0.258 \mathrm{~m}$. SRTM data underestimated the elevation on 20 occasions (87\%) compared to $10(45.45 \%)$ for the TOPO elevations. From the range of height differences $(3.998 \mathrm{~m}$ for the topographic map and $2.77 \mathrm{~m}$ for SRTM), it can be seen that SRTM data are consistently better than those of the topographic map. In Figure 8, the height differences are superimposed on each other.

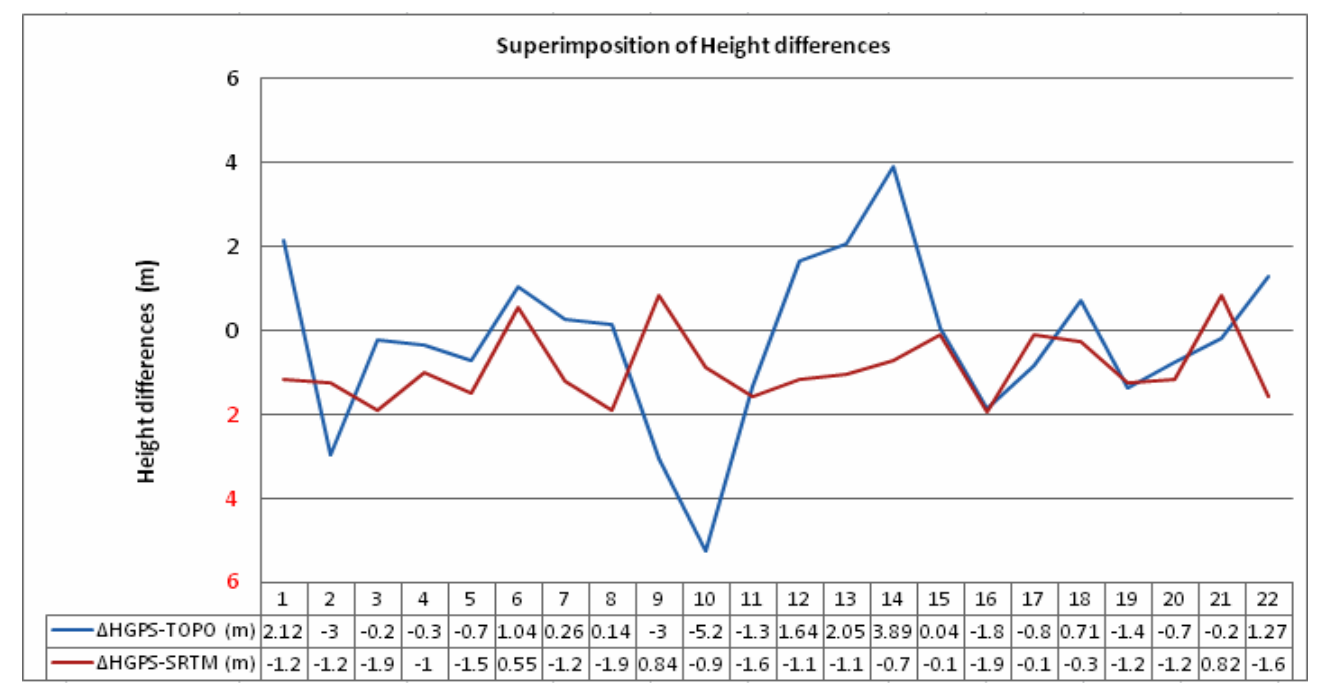

Figure 8: Superimposition of Height differences

\section{Assessment of Cartographic quality}

Figure 9 shows an overlay of contours interpolated at $2.5 \mathrm{~m}$ interval from the SRTM and Topo DEMs. One major requirement for deploying contours for topographic mapping is that the contours must be of good cartographic quality. However, SRTM DEMs have been shown to suffer from a number of gross, systematic and random errors propagated from the Synthetic Aperture Radar (SAR) imaging system. As demonstrated by Koch, A. and Lohmann, P., (2000), SAR imaging system is affected by errors due to baseline tilt angle, baseline length, platform position, phase and slant range.

These errors are known to affect the accuracy and the quality of SRTM DEM and its derivatives such as slope, aspect and contours. In contours interpolated from the SRTM DEMs for example, such errors may manifest as artefacts such as short pieces of unclosed contour lines, self-intersecting contour lines and contour lines intersecting other contour lines with different contour values. The main reason for the non- 
homogeneity in contour pattern in Figure 9 can be attributed to terrain noise errors inherent in the SRTM data.

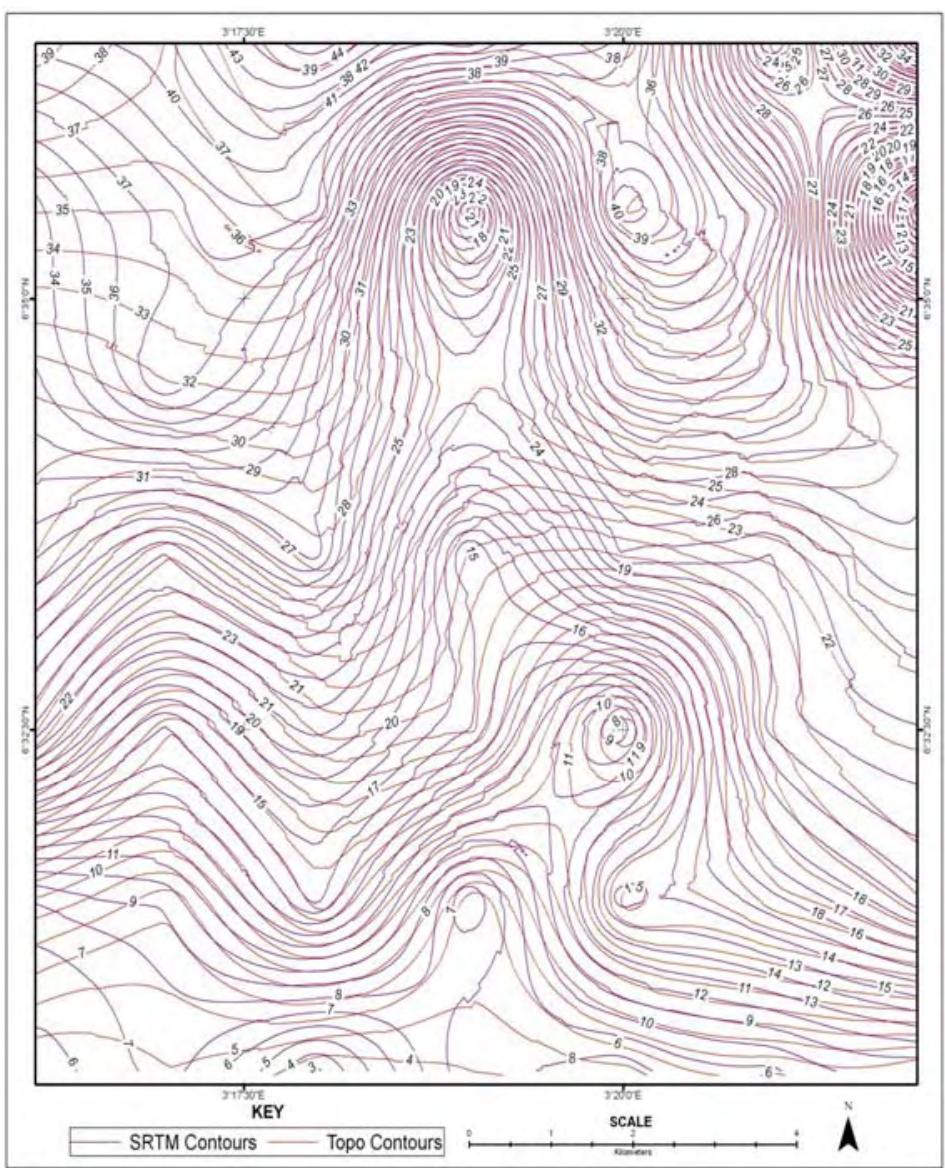

Figure 9: Overlay of SRTM and topographic map contours

\section{Data Validation Model}

By means of regression plots, several equations were tested to see which would provide the most accurate model for the SRTM-TOPO transformation. The discrepancies between the observed height (Нторо) and the computed height of $\mathrm{H}_{\mathrm{s}}$ yielded the least standard deviation $(0.939 \mathrm{~m})$ and the least average absolute error (standard error) $(0.251 \mathrm{~m})$. Thus, the transformation equation for SRTM heights (WGS84 datum) to topographic map heights (in local datum) for the test site is given as (Figure 10, equation 3):

$H_{\text {TOPO }}=1.002 H_{\text {SRTM }}+0.1943$ 
Table 4: Descriptive statistics for the equations

\begin{tabular}{|c|c|c|c|c|c|c|c|c|c|c|c|}
\hline \multirow[t]{3}{*}{ Station } & \multirow[t]{3}{*}{ HGPS } & \multirow[t]{3}{*}{ Hторо } & \multirow[t]{3}{*}{ HsRTM } & \multirow{2}{*}{\multicolumn{2}{|c|}{ Straight line $(y=m x+c)$}} & \multicolumn{6}{|c|}{ Polynomial equation ( $\mathrm{n}^{\text {th }}$ order) } \\
\hline & & & & & & \multicolumn{6}{|c|}{$H_{h 2}(n=2), H_{h 3}(n=3), H_{h 4}(n=4)$} \\
\hline & & & & $\mathrm{Hs}_{\mathbf{s}}$ & $\mathbf{H}_{\text {TOPO }}-\mathrm{Hs}_{\mathbf{s}}$ & $\mathrm{H}_{\mathrm{h2}}$ & $\mathrm{H}_{\text {TOPO }}-\mathrm{H}_{\mathrm{h}}$ & $\mathrm{H}_{\mathrm{h} 3}$ & $\mathrm{H}_{\text {TOPO }}-\mathrm{H}_{\mathbf{3}}$ & $\mathbf{H}_{\mathrm{n} 4}$ & $\mathrm{H}_{\text {TOPO }}-\mathrm{H}_{\mathbf{4}}$ \\
\hline XST 106 & 4.517 & 4.74 & 6.44 & 6.635 & -1.895 & 6.54 & -1.8 & 6.56 & -1.82 & 6.238 & -1.498 \\
\hline XST 111 & 14.876 & 15.212 & 15.895 & 16.137 & -0.925 & 16.41 & -1.198 & 16.473 & -1.261 & 16.693 & -1.481 \\
\hline YTT 2843 & 26.479 & 26.223 & 27.695 & 27.996 & -1.773 & 28.225 & -2.002 & 28.094 & -1.871 & 29.136 & -2.913 \\
\hline YTT 2898 & 10.626 & 11.967 & 12.208 & 12.431 & -0.464 & 12.603 & -0.636 & 12.691 & -0.724 & 12.401 & -0.434 \\
\hline YTT 28127 & 23.124 & 23.08 & 23.243 & 23.522 & -0.442 & 23.833 & -0.753 & 23.775 & -0.695 & 24.723 & -1.643 \\
\hline YTT28 129 & 32.583 & 34.43 & 34.529 & 34.864 & -0.434 & 34.813 & -0.383 & 34.656 & -0.226 & 36.328 & -1.898 \\
\hline YTT 28139 & 31.77 & 32.512 & 32.928 & 33.255 & -0.743 & 33.287 & -0.775 & 33.121 & -0.609 & 34.481 & -1.969 \\
\hline YTT 28148 & 4.703 & 4.895 & 3.884 & 4.066 & 0.829 & 3.811 & 1.084 & 3.744 & 1.151 & 4.174 & 0.721 \\
\hline Standard deviation & 12.511 & 12.641 & 12.700 & 12.764 & 0.939 & 12.774 & 1005 & 12.714 & 1027 & 13.597 & 1433 \\
\hline Variance & 156.515 & 159.797 & 161.301 & 162.914 & 0.881 & 163.185 & 1010 & 161.648 & 1054 & 184.885 & 2.053 \\
\hline Range & 34.481 & 33.202 & 35.030 & 35.205 & 3.281 & 35.131 & 3.380 & 35.126 & 3.413 & 38.329 & 5.282 \\
\hline Minimum & 4.170 & 4.740 & 3.884 & 4.066 & -1895 & 3.811 & -2.002 & 3.744 & -1871 & 4.174 & -4.561 \\
\hline Maximum & 38.651 & 37.942 & 38.914 & 39.271 & 1386 & 38.942 & 1378 & 38.870 & 1542 & 42.503 & 0.721 \\
\hline Standard Error & 3.344 & 3.378 & 3.394 & 3.411 & 0.251 & 3.414 & 0.269 & 3.398 & 0.274 & 3.634 & 0.383 \\
\hline
\end{tabular}




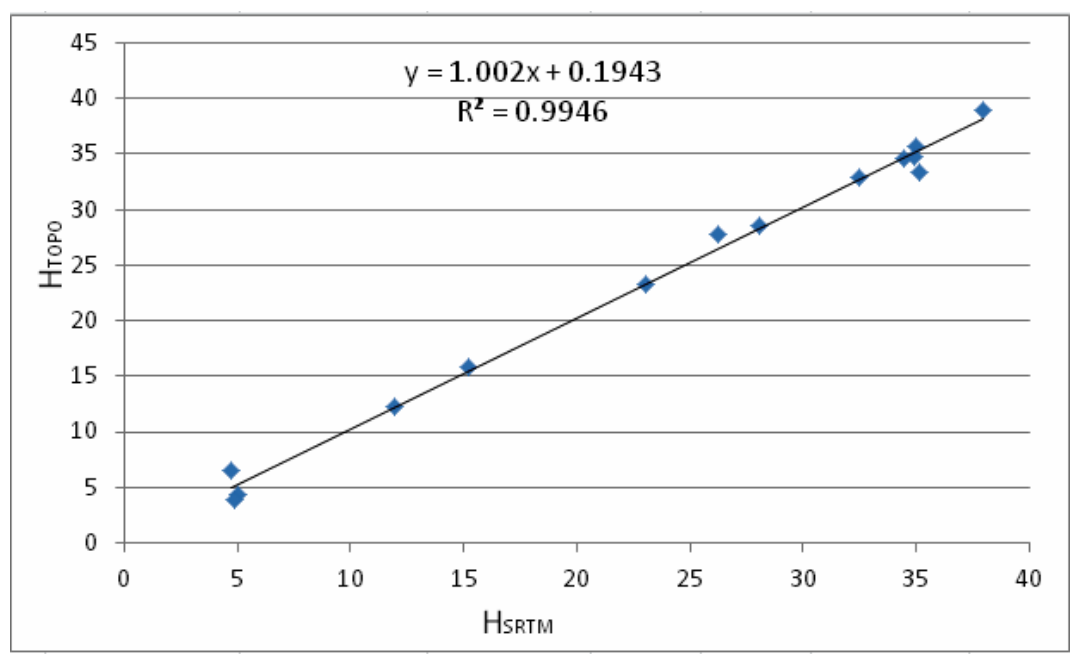

Figure 10: Derivation of a transformation equation

\section{Conclusion and Recommendations}

This study sought to derive a model for transformation of the SRTM heights in WGS84 datum to the Nigerian height system in Minna datum. It also investigated the average absolute errors of the SRTM and topographic maps using the highly accurate GPS points as a controls. The various processing tasks executed were based on the 90$m$ resolution CGIAR-CSI SRTM elevation data, a 1:25,000 topographic map of the test site and DGPS point readings. Analyses presented in this paper indicate that:

- Absolute vertical accuracy of CGIAR-CSI SRTM data for our datasets proved to be higher than the value of $16 \mathrm{~m}$ presented in the original SRTM requirement specification. The average absolute errors of the SRTM DEM and the topographic DEM for our test site was gotten as $+/-0.2351 \mathrm{~m}$ and $+/-0.2803 \mathrm{~m}$ respectively.

- A highly accurate transformation equation was developed for transformation of SRTM heights to Nigerian height system. The equation is given as $\mathrm{H}_{\text {Tоро }}=$ 1.002 H $_{\text {SRTM }}+0.1943$.

- Both SRTM elevation data and elevation data from existing 1:25,000 topographic maps exhibit high positive correlation with the more accurate GPS height data of points within the same site;

- Overlay of the SRTM and topographic map contour maps show that there is a good level of correlation of the terrain in most places while some areas do not correlate at all due to terrain noise inherent in the SRTM data.

These findings therefore indicate that 90-m resolution SRTM elevation data can be used as a substitute for existing small scale topographic maps with the caveat that the former be processed prior to topographic information extraction for 1:25,000 topographical mapping.

The following recommendations are put forward:

- The SRTM data used for this study is the improved SRTM version 4.1 from the Consultative Group for International Agricultural Research-Consortium for Spatial information (CGIAR-CSI). Other research bodies can also improve its current accuracy level by applying more complex void-fill interpolation algorithms 
- Also, when slope and aspect information is available, use of such information by means of incorporating it into a multiple regression model will considerably improve accuracy of CGIAR-CSI SRTM data.

- A prior processing of the SRTM data through resampling and elimination of terrain height errors is recommended to achieve cartographic quality good for small or medium scale topographical mapping.

\section{References}

Blumberg, D., Bach. D., Weissel. J., Gorokhovich, Y., Small, C., and Balk, D., (2005). The 2004 Sumatra Tsunami Event: Contribution of SRTM data to the analysis of devastation. The Shuttle Radar Topography Mission-Data Validation and Applications, Workshop, June 14-16, 2005, Reston, Virginia.

Farr, G., and Kobrick, M., (2000). Shuttle Radar Topography Mission produces a wealth of data, American Geophysical Union, 81, pp. 583-85.

Gorokhovich, Y., and Voustianiouk, A., (2006). Accuracy Assessment of the Processed SRTM-based Elevation Data by CGIAR using field data from USA and Thailand and its relation to the terrain characteristics, Remote Sensing of Environment, $104 \mathrm{pp}$ 409-415.

Jarvis, A., Rubiano, J., Nelson, A., Farrow, A., and Mulligan, M., (2004). Practical use of SRTM data in the Tropics - Comparisons with Digital Elevation Models generated from Cartographic data (unpublished, internal report).

Koch, A., and Lohmann, P., (2000). Quality assessment and validation of digital surface models derived from the shuttle radar topography mission (SRTM). Proceedings, IAPRS, Vol. XXXIII, Amsterdam, 2000.

Madsen, S., and Zebker, H., (1998). Imaging Radar Interferometry. Chapter 6 in Henderson, F.M., A.J. Lewis, ed., Principles and Applications of Imaging Radar, Manual of Remote Sensing, 2, Wiley, NY.

Massonnet, D., (1997). Satellite Radar Interferometry, Scientific American, 276, (Feb.) 46-53.

Rosen, P., Hensley, S., Joughin, I., Li, F., Madsen, S., Rodriguez, E., and Goldstein, R., (2000). Synthetic aperture radar interferometry, Proc. IEEE, 88, 333-382.

Zebker, H., and Goldsten, R., (1986). Topographic Mapping from Interferometer Synthetic Aperture Radar Observations, J. Geophys. Res., 91, (B5). 